\begin{tabular}{|c|c|c|c|c|}
\hline 1893 & $\alpha$ app. & $\delta$ app. & $\log A$ & T. d'ab. \\
\hline $\begin{aligned} & \text { oût } 17 \\
& 18\end{aligned}$ & $\begin{array}{rr}6^{\mathrm{h}} 23^{\mathrm{m}} & 9^{\mathrm{s}} \cdot 34 \\
26 & 40.63\end{array}$ & $\begin{array}{r}+23^{\circ} 18^{\prime} 46^{\prime \prime} .0 \\
23199.2\end{array}$ & $\begin{array}{r}0.16462 \\
16623\end{array}$ & $\begin{array}{r}12^{\mathrm{m}} \quad 8^{\mathrm{s}} .4 \\
11 . \mathrm{I}\end{array}$ \\
\hline 19 & $30 \quad 9.75$ & $2319 \quad 15.2$ & $1678 \mathrm{I}$ & 13.8 \\
\hline 20 & $33 \quad 36.70$ & $2319 \quad 4.4$ & 16936 & 16.5 \\
\hline $2 I$ & $37 \quad 1.49$ & $\begin{array}{lll}23 & 18 & 37.5\end{array}$ & 17089 & 19.1 \\
\hline 22 & 64024.12 & +231755.1 & 0.17239 & 1221.6 \\
\hline
\end{tabular}

Paris 1893 Juin 18.

\begin{tabular}{|c|c|c|c|c|}
\hline I 893 & $\alpha$ app. & $\delta$ app. & $\log A$ & T. d'ab. \\
\hline Août 23 & $6^{\mathrm{h}} 43^{\mathrm{m}} 44^{\mathrm{s}} \cdot 59$ & $+23^{\circ} 16^{\prime} 57^{\prime \prime} 6$ & ‥17387 & $12^{m} 24^{s} \cdot 1$ \\
\hline 24 & $\begin{array}{ll}47 & 2.91\end{array}$ & $\begin{array}{lll}23 & 15 & 45.7\end{array}$ & I $753^{2}$ & 26.6 \\
\hline 25 & $50 \quad 19.07$ & $\begin{array}{lll}23 & 14 & 19.9\end{array}$ & 17674 & 29. \\
\hline 26 & $53 \quad 33.06$ & 231240.6 & 17813 & $3 x$ \\
\hline 27 & $5^{6} 44.90$ & $23 \quad 10 \quad 48.5$ & I 7949 & 33.8 \\
\hline 28 & $\begin{array}{lll}6 & 59 & 54.59\end{array}$ & +23844.1 & 0.18082 & 1236.1 \\
\hline
\end{tabular}

L. Schulhof.

\title{
Eclisse totale di Luna del 15 Novembre 1891
}

\section{osservata a Padova.}

Ingresso nell' ombra terrestre in tempo medio di Padova:

Oggetto osservato

( Primo Lembo

\begin{tabular}{|c|c|}
\hline & I Lembo \\
\hline Grimaldi & II. Lembo \\
\hline & I. Lembo \\
\hline Aristarco & Centro \\
\hline & II. Lembo \\
\hline & I. Lembo \\
\hline Keplero & Centro \\
\hline & II. Lembo \\
\hline & I. Lembo \\
\hline Copernico & Centro \\
\hline & II. Lembo \\
\hline Platone & I. Lembo \\
\hline Platone & II. Lembo \\
\hline Manilio & Centro \\
\hline & I. Lembo \\
\hline Menelao & $\begin{array}{l}\text { Centro } \\
\text { II Lembo }\end{array}$ \\
\hline & oscurato \\
\hline Plinio & Centro \\
\hline Dionisio ir & $\begin{array}{l}\text { ram. oscurat } \\
\text { I. Lembo }\end{array}$ \\
\hline Ticone & Centro \\
\hline & II. Lembo \\
\hline & I. Lembo \\
\hline Proclo & Centro \\
\hline & II. Lembo \\
\hline
\end{tabular}

(C Secondo Lembo

\section{Lorenzoni}

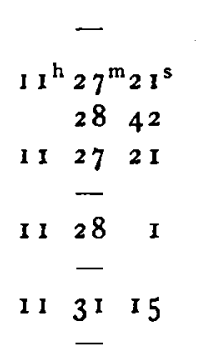

II 3722

$\begin{array}{lll}38 & 22\end{array}$

3932

$39 \quad 52$

$40 \quad 52$

I 498

$$
-
$$

II $53 \quad 5^{2}$

-

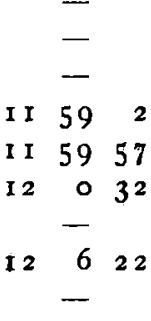

I $24 \quad 52$

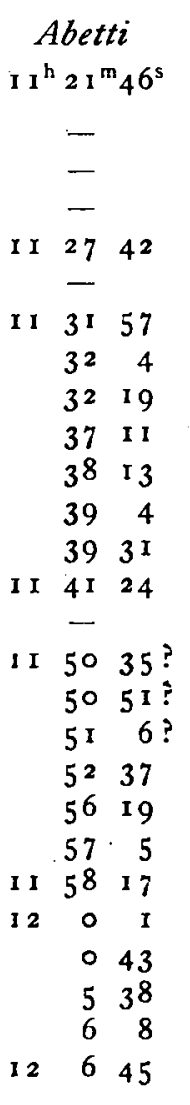

Ciscato

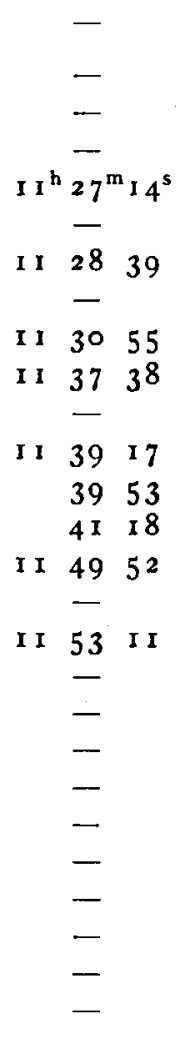

$-$

Lorenzoni osservò col Rifrattore di Starke: obbiett. I I $7 \mathrm{~mm}$, ingr. 87 .

Abetti osservò coll' Equatoriale Dembowski : obbiett. $187 \mathrm{~mm}$, ingr. $9 \mathrm{r}$; solamente il primo contatto col lembo lunare $\mathrm{fu} \mathrm{da}$ lui osservato coll' ingrandimento $2 \mathbf{2} 2$.

Ciscato osservò coll' Equatoriale di Starke: obbiett. I I 7 mm, ingr. 120.

Le ossersazioni furono in generale contrastate dalle nubi.

Padova 1893 Marzo.

G. Lorenzoni.

Inhalt zu Nr. 3171. W. E. Plummer. Rev. Charles Pritchard, D. D., F. R. S. 4r. - T. E. Espin. Stars with remarkable Spectra. 43. G. Müller. Ueber die Lichtstärke des Planeten Mercur. 47. - L. Schulhof. Éléments et éphéméride de la Comète de Finlay 1893 ... 51. - G. Lorensoni. Eclisse totale di Luna del 15 Novembre 1891. 55. 